\title{
PEMANFAATAN KEKAYAAN HAYATI LOKAL: TEH FERMENTASI DARI KELAKAI (Stenochlaena palustris) SEBAGAI PRODUK KEWIRAUSAHAAN
}

\author{
Dede Mahdiyah ${ }^{1}$, Anggrita Sari $^{2}$, Adriana Palimbo ${ }^{3}$, Putri Vidia Sari ${ }^{1}$, Rina Al \\ Kahfi $^{2}$, Fauzi Nurdin ${ }^{1}$ \\ ${ }^{1}$ Fakultas Kesehatan, Program Studi Farmasi, Universitas Sari Mulia \\ ${ }^{2}$ Fakultas Kesehatan, Program Studi Diploma Kebidanan, Universitas Sari Mulia \\ ${ }^{3}$ Fakultas Kesehatan, Program Studi Promosi Kesehatan, Universitas Sari Mulia \\ Email : mahdiyahdede@yahoo.co.id
}

\begin{abstract}
ABSTRAK
Indonesia merupakan negara yang memiliki kekayaan sumber daya alam yang sangat beranekargam, salah satunya adalah keanekaragaman hayati. Salah satu provinsi yang memiliki keanekaragaman hayati yang cukup tinggi adalah di Kalimantan Selatan. Salah satu keanekaragaman hayati yang dimiliki oleh Kalimantan Selatan adalah tumbuhan obat yang berasal dari berbagai daerah, salah satunya adalah tumbuhan kelakai (Stenochlaena palustris). Kelakai merupakan tanaman khas lahan basah (rawa) di Kalimantan Selatan dan ditemukan zat bioaktif utama yaitu quercetin flavonoid yang memiliki efek antiinflamasi. Tujuan kegiatan ini adalah untuk membentuk dan menghasilkan mahasiswa wirausaha baru mandiri dengan program Ipteks bagi Kewirausahaan. Metode yang digunakan pada kegiatan ini meliputi; proses rekrutmen tenant, sosialisasi program, pelatihan kewirausahaan, magang, pendampingan, wirausaha baru mandiri. Diperoleh mahasiswa yang siap untuk menjadi wirausaha baru mandiri yang akan menjalankan wirausaha bidang minuman yaitu teh fermentasi dari tanaman kelakai. Setelah menjalankan kegiatan pelatihan dan magang, mahasiswa siap menjadi tenant baru dengan program yaitu memproduksi teh fermentasi dari kelakai untuk dipasarkan ke lingkungan kampus dan juga ke masyarakat luas melalui media sosial dan aplikasi berbasis web dan android (ibksarimulia). Program ini membentuk mahasiswa memiliki jiwa wirausaha dan mampu menjalankan usaha dengan baik di bidang minuman teh fermentasi dari kelakai.
\end{abstract}

Kata Kunci: Kelakai, Mahasiswa wirausaha, Teh Fermentasi, Tenant.

\section{PENDAHULUAN}

Universitas Sari Mulia merupakan Perguruan Tinggi Swasta yang berada di Banjarmasin, Kalimantan Selatan. Universitas Sari Mulia memiliki visi unggulan yaitu peningkatan potensi kekayaan hayati lokal dan Kewirausahaan, sehingga untuk mencapai visi unggulan tersebut terdapat kegiatan kewirausahaan di kampus dalam bentuk soft skill kemahasiswaan yang dilaksanakan setiap seminggu sekali pada hari Rabu. Kegiatan soft skill mendidik dan melatih bakat, inovasi, dan kreativitas mahasiswa untuk menciptakan mahasiswa yang memiliki keunggulan lebih yaitu jiwa wirausaha, kegiatan ini dibimbing oleh dosen.

Ipteks bagi Kewirausahaan (IbK) merupakan program hibah dari 


KemenristekDikti yang sekarang
berubah namanya menjadi PPK
(program

Kewirausahaan). Program ini dibuat dan dilaksanakan di Universitas Sari Mulia oleh dosen untuk membimbing, melatih, dan membina mahasiswa yang siap menjadi tenant dan wirausaha baru yang handal dan unggul dalam jenis wirausaha yang dipilih. Kegiatan ini mendapat respon sangat baik dari mahasiswa sehingga banyak mahasiswa yang tertarik untuk mengikuti program ini. Program ini mulai dari tahun 2016 sampai dengan tahun 2019, dan akan terus berlangsung untuk menumbuhkan wirausaha-wirausaha baru mandiri dari mahasiswa Universitas Sari Mulia dengan beragam jenis wirusaha. Salahsatu wirausaha yang ada di program IbK ini adalah teh fermentasi dari tanaman kelakai, yang merupakan tanaman khas dari Kalimantan dengan tujuan untuk mengangkat nilai lokal menjadi nasional.

Kelakai merupakan tanaman pakupakuan yang hidup dilahan gambut dan banyak ditemukan di daerah Kalimantan.

Kelakai merupakan tanaman yang dijadikan sebagai makanan sayuran oleh masyarakat Kalimantan, selain itu juga digunakan oleh ibu nifas untuk memperlancar ASI dengan cara mengkonsumsi setiap hari, baik itu dijadikan sayuran maupun minuman rebusan kelakai.

$$
\text { Hasil laporan penelitian }
$$
menyebutkan bahwa kelakai dapat meningkatkan volume ASI (Sutomo \& Anggraini, 2010), dapat menyembuhkan anemia, sebagai pereda demam, antibakteri (Liu, Orjala, Sticher, \& Rali, 1999), juga dengan kandungan gizi yang sangat baik didalamnya dijadikan makanan olahan oleh mahasiswa IbK tahun lalu yaitu Bakmie Kelakai (Mahdiyah, Sari, \& Palimbo, 2017).

Kelakai juga memiliki khasiat yang baik untuk kesehatan yaitu memiliki kandungan antioksidan tinggi (Chai, Panirchellvum, Ong, \& Wong, 2012), mencegah infeksi sehingga daun kelakai diproses dengan cara difermentasi agar memiliki nilai manfaat yang baik bagi kesehatan. Selain itu berdasarkan analisis kandungan nutrisi bahwa kelakai memiliki kandungan kalium dan fosfor yang baik(Voon \& Kueh, 1999).

Banyak hasil studi sebelumnya tentang kelakai untuk kesehatan (Liu et al., 1999), sehingga memungkinkan dapat dikembangkan menjadi makanan dan minuman olahan yang unik, kreatif, 
inovatif dan bernilai gizi serta berdaya saing didunia wirausaha.

Program IbK/PPK ini bertujuan untuk melatih dan membentuk mahasiswa menjadi wirausaha baru mandiri agar menjadi mahasiswa yang unggul tidak hanya dibidang kebidanan saja tetapi juga dibidang kewirausahaan yang berdaya saing. Tingginya nilai potensi kewirausahaan dari tanaman kelakai merupakan tantangan dan peluang bagi para dosen di Universitas Sari Mulia untuk mengembangkan program kewirausahaan bagi mahasiswa dan melahirkan mahasiswa wirausaha baru. Selain melimpahnya kelakai sebagai sumber daya alam di Kalimantan Selatan yang memiliki banyak manfaat kesehatan juga perlunya skill mahasiswa yang mampu mengelola wirausaha, sehingga program IbK di AKBID Sari Mulia dibuka untuk melatih, mendampingi dan melahirkan mahasiswa handal dalam berwirausaha.

\section{METODE PELAKSANAAN}

a. Sosialisasi Program IbK/PPK

Sosialisasi program IbK dilakukan oleh dosen kepada seluruh mahasiswa Universitas Sari Mulia, sosialisasi dilakukan pada awal tahun setelah pengumuman hibah ini didanai (Mahdiyah et al., 2020).

b. Perekrutan Tenant

Perekrutan tenant dari mahasiswa setelah dilakukan soialisasi program IbK ke mahasiswa, mahasiswa kemudian tertarik dan daftar memilih tenant dan siap mengikuti program.

c. Pelatihan

Kegiatan ini dilangsungkan untuk melatih mahasiswa dalam berwirausaha, yaitu mahasiswa yang sudah daftar dan siap mengikuti program akan diberikan pelatihan tentang manajemen wirausaha, mulai dari organisasi wirausaha, karakteristik wirausaha, cara menghitung modal, cara mengelola usaha, cara menentukan harga, dan cara mengendalikan serta mempertahankan usaha.

d. Magang

Kegiatan ini bertujuan untuk melatih mahasiswa dalam mengenal dunia usaha nyata. Kegiatan ini dilaksanakan ditempat usaha yang sudah berjalan yaitu yang sesuai dengan jenis usaha teh kelakai.

e. Pendampingan

Kegiatan ini dilaksanakan oleh dosen yang menjalankan program IbK/PPK untuk mendampingi mahasiswa 
dalam kegiatan berwirausaha agar menghasilkan mahasiswa yang siap menjadi wirausaha baru mandiri.

f. Mahasiswa wirausaha baru mandiri Individu/kelompok mahasiswa yang sudah mengikuti proses diatas untuk menjadi wirausaha baru yang handal, kreatif, inovatif, dan berdaya saing di usaha nyata.

g. Monitoring dan Evaluasi

Kegiatan ini dilaksanakan setiap kali program dilaksanakan, yaitu setelah pelatihan, setelh magang, dan saat pendampngan sehingga dapat memantau dan menilai serta memilih mahasiswa mana yang siap menjadi wirausaha baru mandiri.

\section{HASIL DAN PEMBAHASAN}

\section{a. Kegiatan Sosialisasi Program}

Kegiatan ini dilaksanakan di Kampus Universitas Sari Mulia pada bulan Januari 2018, kegiatan ini diikuti oleh mahasiswa. Tim PPK bekerjasama dengan LPPM Universitas Sari Mulia untuk menjalankan program PPK ini.

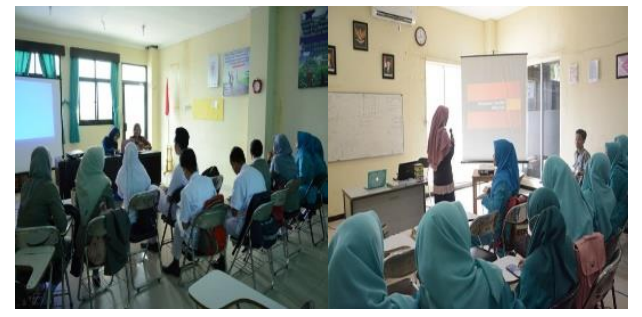

Gambar 1. Sosialisasi Program IbK/PPK di AKBID Sari Mulia
Kegiatan sosialisasi ini berlangsung dalam satu hari yang dilaksanakan oleh dosen yang memperoleh program hibah PPK dari kemenristekDikti. Kegiatan ini bertujuan untuk mensosialisasikan program PPK yang akan dijalankan di AKBID Sari Mulia kepada mahasiswa yang berminat menjadi wirausaha.

\section{b. Perekrutan Tenant}

Pada kegiatan perekrutan mahasiswa untuk menjadi seorang tenant/ sekelompok tenant, maka sebelumnya mahasiswa mendaftarkan diri dulu kepada Dosen yang memiliki program PPK untuk mengikuti program tersebut dan siap mengikuti semua kegiatan sampai selesai dengan mengisi formulir pendaftaran. Mahasiswa yang sudah mendaftar memilih jenis wirausaha sesuai dengan keinginannya dan akan mengikuti ke tahap selanjutnya untuk menjadi seorang/sekelompok tenant wirausaha baru mandiri.

\section{c. Pelatihan}

Pelatihan yang diberikan kepada mahasiswa yang mengikuti program IbK/PPK ini berupa pelatihan kewirausahaan yaitu tentang karakteristik wirausaha, 
organisasi, manajemen usaha, cara mengendalikan usaha, dan juga materi tentang pelatihan yang terkait dengan jenis wirausaha yang akan diikuti yaitu pengolahan minuman. selain itu kegiatan pelatihan bertujuan untuk membentuk karakter wirausaha yang tangguh dan mandiri. Hal ini juga dinyatakan dalam kegiatan pengabdian yang lain yaitu pelatihan hardiness dapat memicu siswa memiliki pemaham mengenai ketangguhan (Arsyad \& Sulistiyana, 2021). Berikut adalah kegiatan pelatihan kewirausahaan yang dilaksanakan pada kegiatan pengabdian ini.

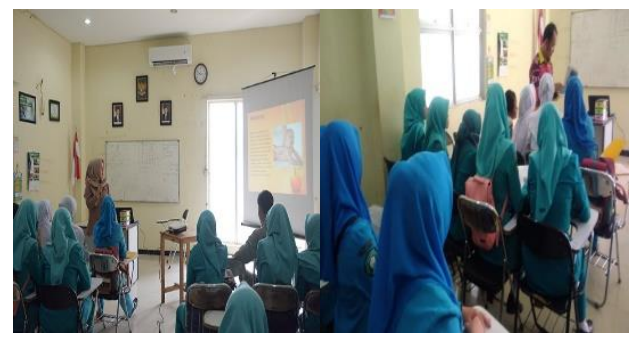

Gambar 2. Kegiatan pelatihan wirausaha program IbK/PPK

\section{d. Magang Ke Mitra Program} IbK/PPK

Kegiatan magang ini
dilakukan untuk memberikan
pengetahuan kepada mahasiswa
tentang cara mengelola usaha,
menambah wawasan tentang
berwirausaha, mahasiswa juga dapat
merumuskan analisis SWOT tentang

kewirausahaan yang akan dijalankannya nanti, sehingga siap menjadi mahasiswa wirausaha yang siap terjun ke dunia usaha nyata yang sudah dibekali dengan ilmu yang memadai. Mitra disini adalah pengusaha makanan dan minuman sehingga dapat menjadi contoh dan inspirasi mahasiswa dalam mengelola usaha.

\section{e. Pendampingan}

Mahasiswa yang sudah mengikuti kegiatan pelatihan dan magang selanjutnya mulai dilatih dalam berwirausaha, yaitu usaha teh fermentasi daun kelakai. Mahasiswa akan didampingi mulai dari cara mengelola usaha sampai ke pemasaran produknya dengan tujuan agar nantinya mahasiwa tersebut mahir dan handal dalam mengelola usahanya sendiri.

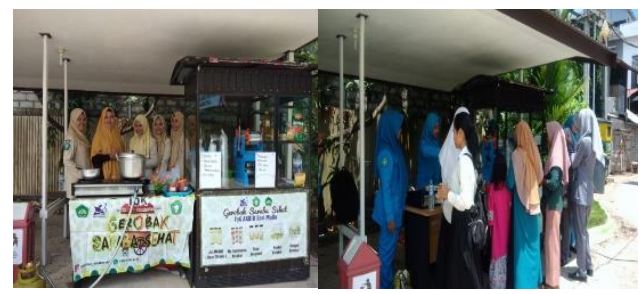

Gambar 3. Pendampingan mahasiswa dalam menjalankan kegiatan usaha.

\section{f. Monitoring dan Evaluasi}

Kegiatan monitoring dan evaluasi ini dalaksanakan setiap tiga bulan sekali dengan tujuan untuk 
meninjau, menilai, dan mengevaluasi kegiatan wirausaha yang dijalankan oleh mahasiswa, sehingga dapat ditemukan titik solusi kendala yang dihadapi untuk kemajuan wirausahanya.

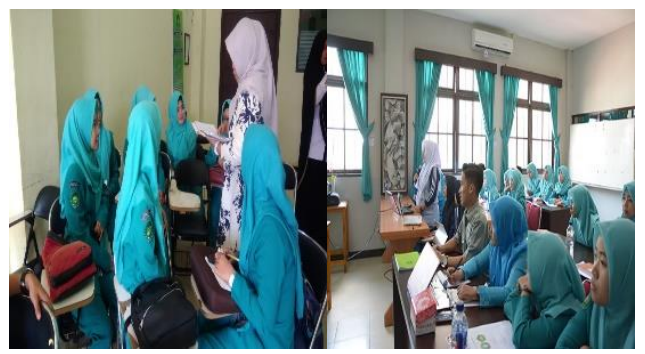

Gambar 4. Kegiatan monitoring dan evaluasi program IbK/PPK yang dilaksanakan oleh dosen kepada mahasiswa.

\section{g. Wirausaha Baru Mandiri}

Mahasiswa yang sudah siap menjalankan wiraushanya sendiri ataupun perkelompok dan siap mengelola usaha dengan baik agar program ini terus berjalan sampai mahasiswa tersebut sukse menjadi entepreuner muda yang kreatif, inovatif dan memberikan pengaruh positif untuk generasi bangsa. Produk usaha yang dihasilkan adalah teh fermentasi dari daun kelakai, yaitu daun kelakai yang dikeringkan kemudian direbus lalu dicampur dengan starter mikroorganisme kemudian ditambahakan dengan sumber karbon yaitu gula untuk menghasilkan teh fermentasi.
Mahasiswa juga dibekalai tentang pemasaran produk dengan berbagai media yaitu media sosial seperti instagram, Whatsapp, dan juga program ini akan dimuat dalam aplikasi android dengan nama ibksarimulia. Selain diajarkan berwirausaha mahasiswa juga dikenalkan technopreneurship. Technopreneurship memiliki banyak keunggulan karena menggunakan media internet sehingga jangkauannya lebih luas, dengan tujuan agar mahasiswa melek akan teknologi yang bisa diimplementasikan dalam usaha (Retnosari, Setiadi, Hijriana, \& Rahman, 2021).

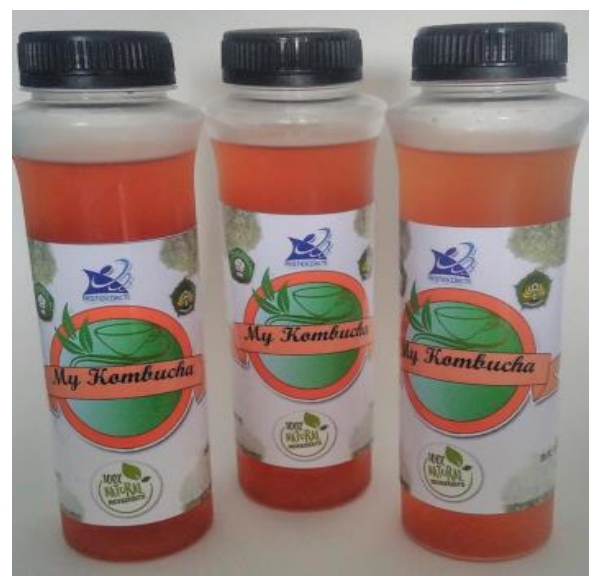

Gambar 5. Produk teh fermentasi daun kelakai hasil kreatifitas mahasiswa wirausaha program $\mathrm{IbK} / \mathrm{PPK}$.

\section{KESIMPULAN}

Kegiatan program IbK di Universitas Sari Mulia mampu 
melahirkan mahasiswa yang siap menjadi seorang wirausaha baru dan mandiri dengan mengelola usaha yang mengangkat nilai potensi kekayaan hayati lokal di Kalimantan Selatan yaitu teh fermentasi dari daun kelakai. Tentunya program ini melalui beberapa tahapan kegiatan agar mencetak mahasiswa yang unggul, kreatif, inovatif dan berdaya saing dalam bidang usaha yang dilakukannya agar terus berkelanjutan.

\section{DAFTAR PUSTAKA}

Arsyad, M., \& Sulistiyana. (2021). Pelatihan Hardiness Sebagai Upaya Pembentukan Karakter Tangguh (Hardiness) Dalam Menghadapi Pembelajaran Jarak Jauh Di Masa Pandemi Covid-19. Jurnal Pengabdian Al-Ikhlas, 7(1), 22-32.

Chai, T. T., Panirchellvum, E., Ong, H. C., \& Wong, F. C. (2012). Phenolic contents and antioxidant properties of Stenochlaena palustris, an edible medicinal fern. Botanical Studies, 53(4), 439-446.
Liu, H., Orjala, J., Sticher, O., \& Rali, T. (1999). Acylated flavonol glycosides from leaves of Stenochlaena palustris. Journal of Natural Products, 62(1), 55-70.

Mahdiyah, D., Sari, A., \& Palimbo, A. (2017). IbK Di Akbid Sari Mulia: Olahan Makanan Sehat Dari Kelakai (Stenochlaena palustris). In Seminar Nasional dan gelar Produk (pp. 1213-1223).

Mahdiyah, D., Sari, A., Palimbo, A., Darsono, P. V, Nurdin, F., Dona, S., \& Alawiyah, T. (2020). The Use of Natural Resources in Southern Kalimantan for the Development of Student Entrepreneurship. International Journal of Advanced Science and Technology, 29(03), 5044-5051.

Retnosari, D., Setiadi, B., Hijriana, N., \& Rahman, A. (2021). Pelatihan Dan Pengembangan Teknologi Technopreneurship Untuk Guru Dan Siswa Pada Smk Gema Kalimantan Kabupaten Banjar. Jurnal Pengabdian Al-Ikhlas, 7(1), 70-77.

Sutomo, D., \& Anggraini, D. (2010). Makanan sehat pendamping ASI.

Voon, B., \& Kueh, H. (1999). The nutritional value of indigenous fruits and vegetables in Sarawak. Asia Pac. J. Clin. Nutr, 8, 24-31. 